\title{
Impact mitigating capabilities of a spray-on elastomer coating applied to concrete \\ C. Fallon ${ }^{\mathrm{a}}$, G.J. McShane ${ }^{\mathrm{a}, *}$ \\ ${ }^{a}$ Department of Engineering, University of Cambridge, Trumpington Street, Cambridge CB2 1PZ, UK
}

\begin{abstract}
Structural protection against the effects of a nearby explosive detonation is an area of growing importance. Spray-on elastomer coatings are of interest as a practical and low cost protective solution. Recent research has demonstrated the effectiveness of such coatings for blast mitigation. However, there are two loading scenarios of concern for these applications: blast pressures and fragment impacts. To date, there remains a need to understand the merits of this protective solution for impact indentation of concrete structural elements. In this work, we examine whether, and by what mechanism, an elastomer coating can offer protection in this case. A series of quasi-static indentation and dynamic impact experiments are performed using a $0.1 \mathrm{~kg}$ circular cylindrical (i.e. blunt) projectile. It is demonstrated that the coating displays a significant protective capability over the full range of impact velocities considered, c. $45-150 \mathrm{~m} \mathrm{~s}^{-1}$. The coating remains intact until impacted at a velocity of c. $120 \mathrm{~m} \mathrm{~s}^{-1}$ when it fails by a ductile, tearing mechanism, forming a plug which undergoes large elastic contraction after projectile penetration. A finite element model of the impact indentation of uncoated and coated concrete cubes is developed and validated against the experiments. Focusing on the early time steps and damage initiation in the concrete, the numerical model is used to interrogate the mechanism by which the elastomer achieves its mitigating effect. It is found that the way in which the elastomer alters the stress distribution in the concrete, and its time evolution, is key to its performance. These findings provide a basis for optimising protective coatings for concrete structural elements.

Keywords: impact, concrete, elastomer
\end{abstract}

\footnotetext{
${ }^{*}$ Corresponding author

Email addresses: cf335@cam.ac.uk (C. Fallon), gjm31@cam.ac.uk (G.J. McShane)
} 


\section{Introduction}

With growing global security concerns, there is an increased impetus to develop new strategies to protect critical infrastructure from the detrimental effects of blast and fragment impact. Design for extreme load events in the built environment must consider a number of constraints. Although performance is key, cost-effectiveness, ease of installation, low maintenance and aesthetics are important. Structural retrofit is one answer to this problem, and a particularly practical solution that has been gaining attention is the application of a spray-on elastomer coating.

Most studies to date have tended to focus on the mitigating capabilities of such coatings in response to blast pressure pulses. Promising results have been reported for coatings applied

to masonry [1, 2], steel [3, 4] and reinforced concrete [5-7] substrates. However, relatively few investigations have been performed to assess the influence of an elastomer coating on the damage due to fragment impact. Studies have been performed on elastomer-metallic bilayer and laminate plates [8-19], though there still exists some debate on the influence of the coating location (impacted or distal face), construction (bilayer, sandwich or laminate) and mechanism by which the elastomer achieves its mitigating effect. Researchers have postulated that an elastomer layer on the impacted face gives rise to energy dissipation via an impact-induced glass transition $[11,12]$ while some report it serves to stabilise the onset of necking in the metal $[16,17]$. Others have argued that when positioned on the impacted face, the elastomer serves to alter the effective nose shape of the indenter - changing the deformation mode in the metal layer $[18,19]$.

Despite the encouraging results achieved with metal substrates, to the authors' knowledge, there has been no exploration into how the elastomer performs when applied to concrete structures, subjected to projectile impact. Concrete represents a significant proportion of today's ageing infrastructure, and would be an ideal candidate to benefit from an effective retrofit solution. One concrete retrofit strategy that has been investigated for physical protection is the use of fibre reinforced polymers (FRP). Pham and Hao [20] present a review of the studies performed to assess the impact resistance of reinforced concrete (RC) beams, slabs and columns, strengthened with FRP and conclude that, while further research is required, FRP retrofits can indeed enhance impact resistance of RC. However, if competitive, a 
spray-application elastomer would offer significant benefits in terms of practicality and cost.

In this study, we will use experimental and numerical techniques to examine the influence of a typical spray-on elastomer coating, applied to the impacted face of a concrete cube, subjected to projectile impacts between $45-150 \mathrm{~ms}^{-1}$. An experimental programme is followed to first establish if, and over what range of impact velocities, the elastomer coating has a damage mitigating effect. A $0.1 \mathrm{~kg}$ circular cylindrical (i.e. blunt) projectile is used. The projectile geometry chosen for this study is idealised, simpler than a typical fragment simulating projectile (FSP). However, it allows us to study in a well controlled way the target's response to a sharp edged projectile. The axisymmetric geometry also simplifies the numerical analysis of the experiments, as discussed subsequently. A numerical model of the quasi-static indentation and dynamic impact of a concrete specimen is developed using the commercially available finite element analysis (FEA) software, Abaqus/Explicit [21]. We validate this model against the experimental cases and establish under what circumstances we deem the model to be an appropriate analysis tool. The validated numerical model is then used to interrogate the coating's influence on damage initiation in the concrete substrate, thus revealing details of the underlying protective mechanisms.

\section{Projectile impact experiments}

Projectile impact tests are performed using a gas gun apparatus, illustrated in Fig. 1. A blunt (i.e. circular cylindrical) steel projectile of diameter $28.5 \mathrm{~mm}$, length $20 \mathrm{~mm}$ and mass $0.1 \mathrm{~kg}$ is fired at a concrete cube, of side length $100 \mathrm{~mm}$, supported on its back face and resting upon a wooden block support.

Two configurations are tested: (i) the concrete in its uncoated state and (ii) the concrete with an elastomer layer, approximately $5 \mathrm{~mm}$ thick, placed on its impacted face. The elastomer layer is not bonded to the concrete and is in frictional contact only. Small pieces of double-sided adhesive tape, located at each corner, are used to ensure the correct initial positioning of the layer. 


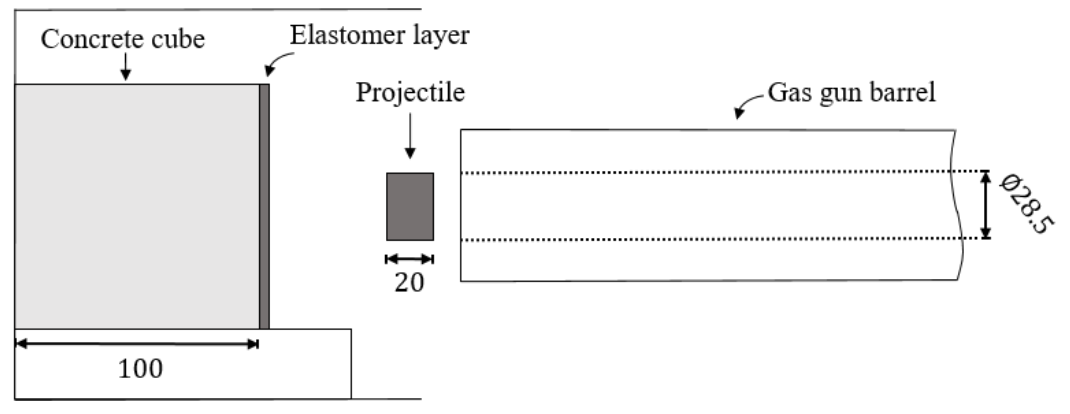

Figure 1: Schematic of the gas gun apparatus used for the impact tests (not to scale). All dimensions are in mm.

The elastomer layer was chosen to be a commercially available spray application, polyurea /polyurethane hybrid. The coatings were obtained by spraying the polymer onto an untreated steel plate and then peeling it off. ${ }^{1}$ Note, this technique resulted in the thickness of the elastomer layer varying by approximately $15 \%$ between tests since precise control of the thickness was not possible. The thickness of the elastomer layer in each test is tabulated in Appendix A.

Concrete cubes, of side length $100 \mathrm{~mm}$ were designed and cast. The Department of Environment mix design method [23] is employed to achieve a characteristic strength at 28 days of $40 \mathrm{MPa}$. The characteristic strength is defined as the cube strength below which not more than $5 \%$ of test results fall. Assuming normal distribution and good mix control, the mix must be designed to have a target mean strength equal to the desired characteristic strength plus 1.64 times the expected standard deviation (in this case, we choose $4.5 \mathrm{MPa}$ according to the guidance in [23]). Thus, a target mean strength of $47 \mathrm{MPa}$ is designed for. Rapid-hardening Portland Cement is used with uncrushed coarse gravel aggregate of maximum size $10 \mathrm{~mm}$. The mix is designed to have high workability with $60-180 \mathrm{~mm}$ slump. In terms of volume \%, the final design mix ratio is chosen as follows - cement: water: fine aggregate (sand): coarse aggregate $=15 \%: 23 \%: 28 \%: 34 \%$. After 28 days, a compressive test was performed on a concrete cube using an Instron screw-driven materials

\footnotetext{
${ }^{1}$ The polymer specimens were the commercially available LINE-X product, supplied courtesy of I. Mohagheghian, University of Cambridge [22]. Further details on the coating and its application process can be found in [22].
} 
testing machine at a nominal strain rate, $\dot{\epsilon}=10^{-3} \mathrm{~s}^{-1}$. The nominal stress-strain response, corrected for cross-head compliance is presented in Fig. 2, illustrating that a compressive strength of $47 \mathrm{MPa}$ is attained.

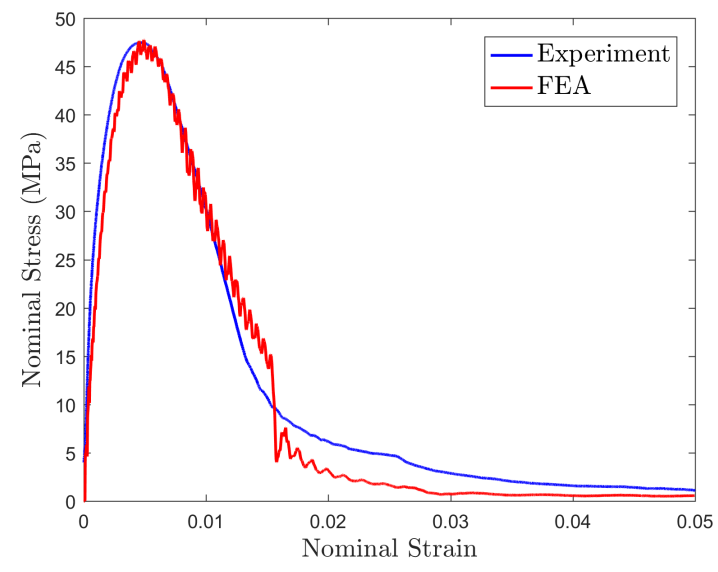

Figure 2: Nominal compressive stress-strain response of a $100 \mathrm{~mm}$ concrete cube, tested at a nominal strain rate $\dot{\epsilon}=10^{-3} \mathrm{~s}^{-1}$. Also plotted is the FE model prediction discussed subsequently.

\subsection{Results}

Impact tests are performed for projectile velocities spanning the range 45 and $145 \mathrm{~m} \mathrm{~s}^{-1}$. Coated and uncoated cubes are tested at each impact velocity, and the level of damage is assessed. The projectile diameter was machined to match closely the internal diameter of the gun barrel, thus helping to ensure a repeatable, normal impact. This was verified using high speed photography (at 49000 frames per second) which showed that for all tests, a normal impact was achieved, within $\pm 3^{\circ}$. An example of the high speed photography is shown in Fig. 3. Images of the specimens post-impact are presented in Figs. 4 - 8 . 


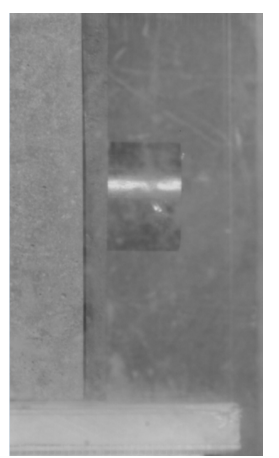

(a) $t=0 \mu \mathrm{s}$

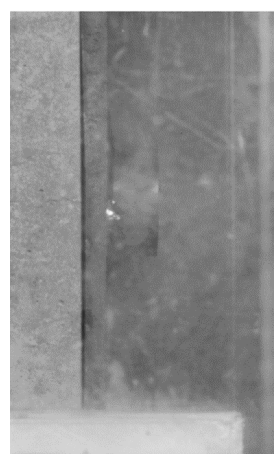

(b) $t=82 \mu \mathrm{s}$

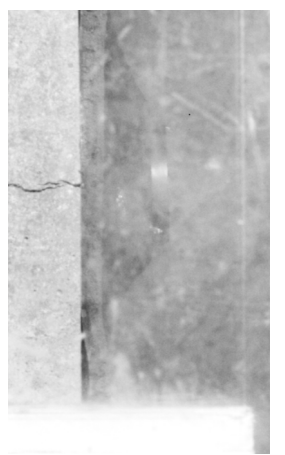

(c) $t=286 \mu \mathrm{s}$

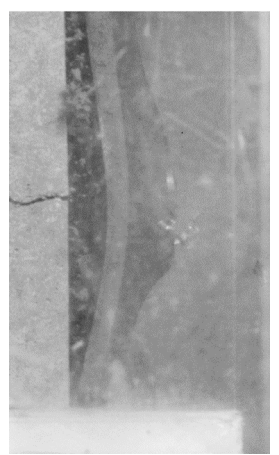

(d) $t=960 \mu \mathrm{s}$

Figure 3: High speed photographs of the impact test performed for a coated specimen at a projectile impact speed of $124 \mathrm{~m} \mathrm{~s}^{-1}$. The time $t=0 \mu \mathrm{s}$ corresponds to first contact with the elastomer coating.

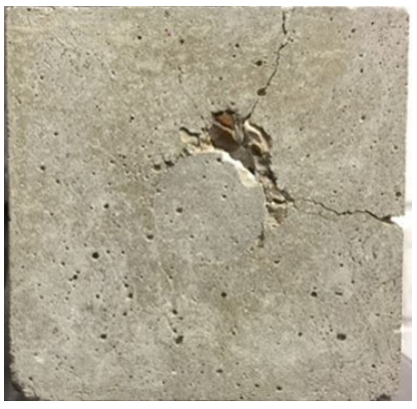

(a) Uncoated concrete

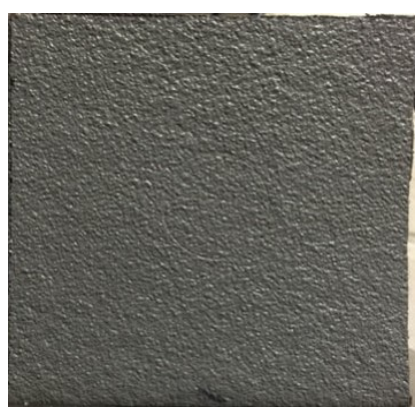

(c) Coating - impacted

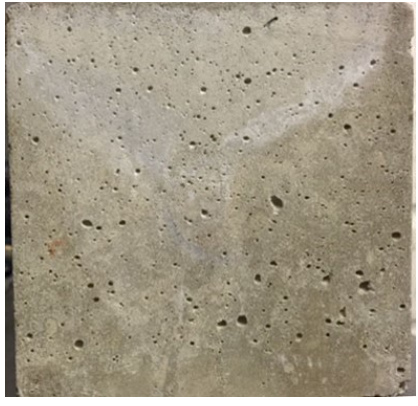

(b) Coated concrete

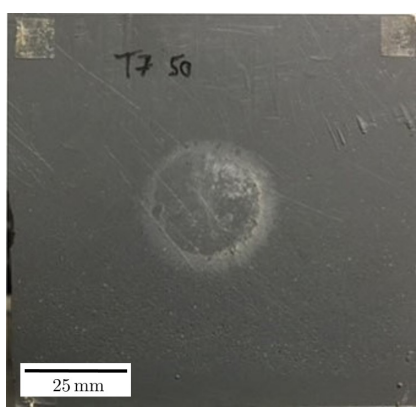

(d) Coating - distal face

face

Figure 4: Photographs of the test specimens for a projectile impact velocity of $45 \mathrm{~m} \mathrm{~s}^{-1}$ for both uncoated and coated specimens. The elastomer thickness for the coated specimen was $5.53 \mathrm{~mm}$. 


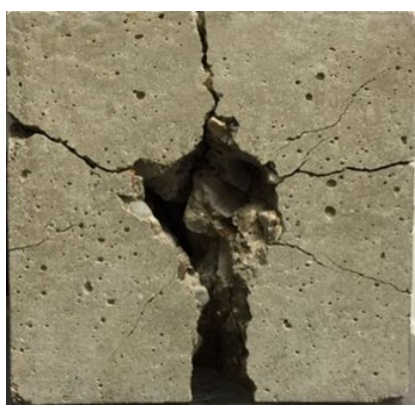

(a) Uncoated concrete

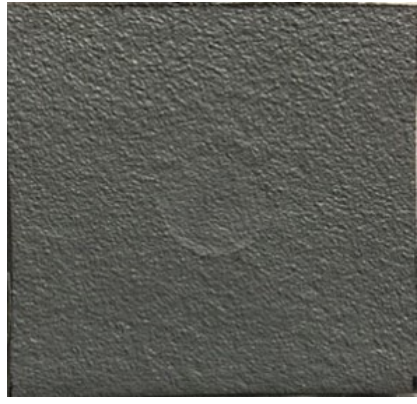

(c) Coating - impacted

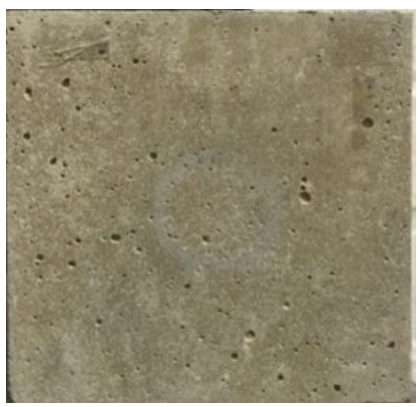

(b) Coated concrete

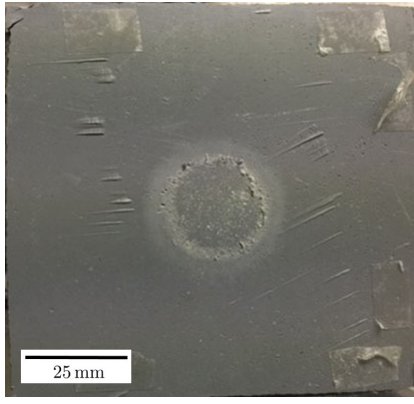

(d) Coating - distal face

face

Figure 5: Photographs of the test specimens for a projectile impact velocity of $68 \mathrm{~m} \mathrm{~s}^{-1}$ for the uncoated specimen and $64 \mathrm{~ms}^{-1}$ for the coated specimen. The elastomer thickness for the coated specimen was $5.35 \mathrm{~mm}$. 


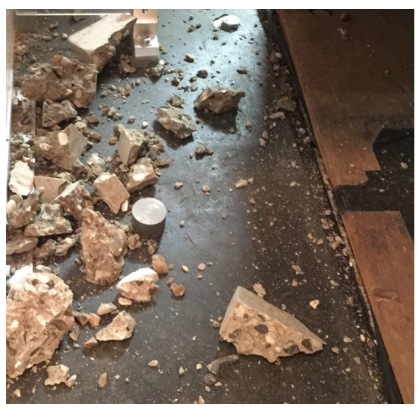

(a) Uncoated concrete

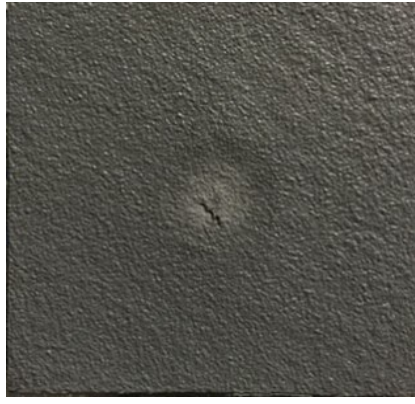

(c) Coating - impacted

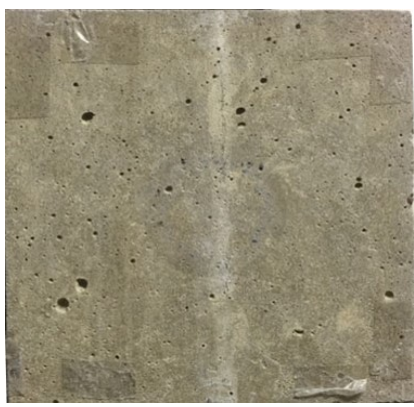

(b) Coated concrete

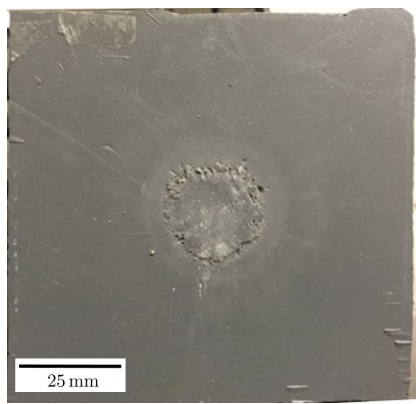

(d) Coating - distal face

face

Figure 6: Photographs of the test specimens for a projectile impact velocity of $100 \mathrm{~m} \mathrm{~s}^{-1}$ for the uncoated specimen and $101 \mathrm{~m} \mathrm{~s}^{-1}$ for the coated specimen. The elastomer thickness for the coated specimen was $6.02 \mathrm{~mm}$. 


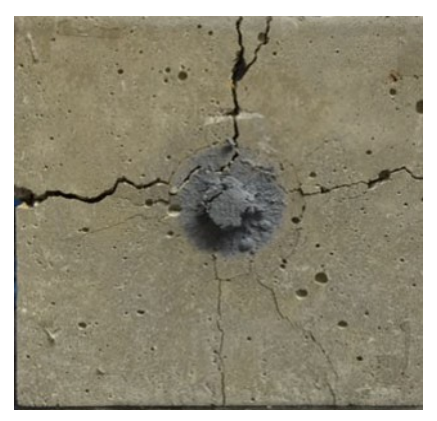

(a) Coated concrete

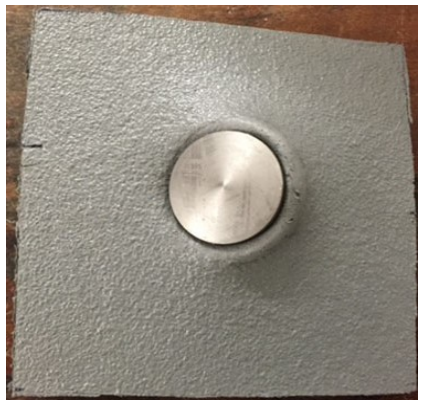

(b) Coating - impacted

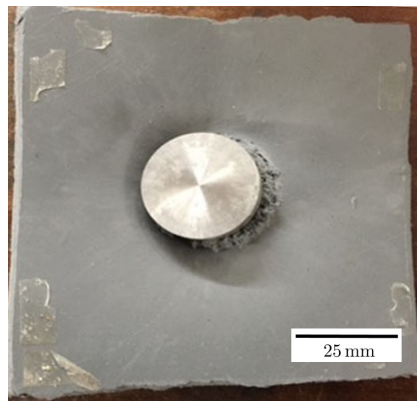

(c) Coating - distal face face

Figure 7: Photographs of the coated test specimen for a projectile impact velocity of $124 \mathrm{~m} \mathrm{~s}^{-1}$. The elastomer thickness was $5.21 \mathrm{~mm}$. 


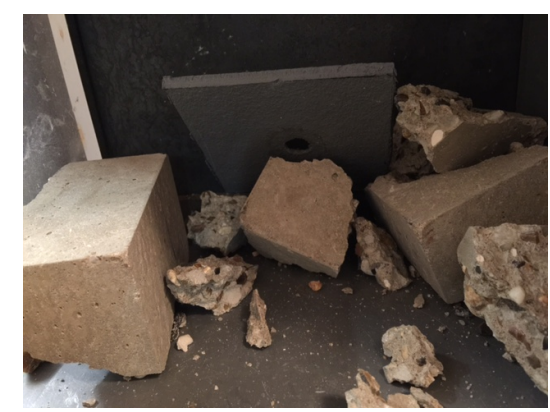

(a) Coated concrete

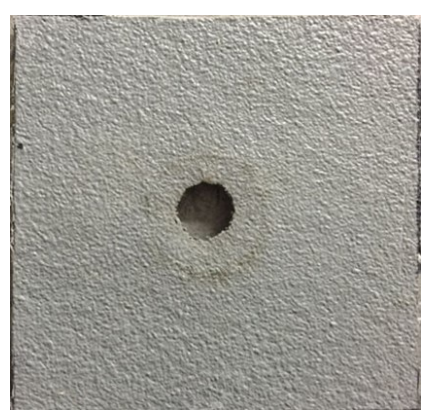

(b) Coating - impacted face

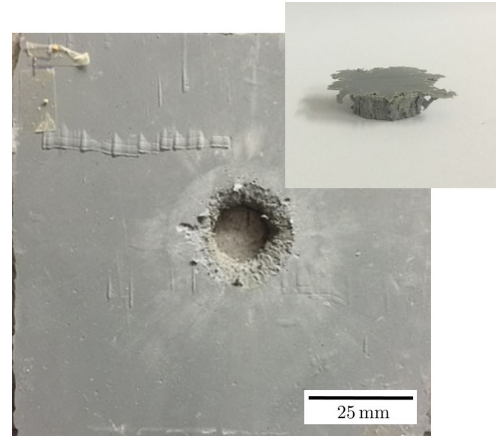

(c) Coating - distal face with

polymer plug (inset)

Figure 8: Photographs of the coated test specimen for a projectile impact velocity of $142 \mathrm{~m} \mathrm{~s}^{-1}$. The elastomer thickness was $5.36 \mathrm{~mm}$.

\subsection{Discussion}

We observe a substantial, beneficial effect of the elastomer coating across the full range of velocities tested. For the uncoated concrete, increasing the projectile speed increases the extent of damage and radial cracking, as shown in Figs. 4 - 6. At speeds of $100 \mathrm{~ms}^{-1}$ and beyond, the cube is entirely fragmented. For the coated concrete cubes, there is no evidence of concrete damage (based on visual inspection) for impact speeds up to and including $100 \mathrm{~m} \mathrm{~s}^{-1}$. Further, below impact speeds of $100 \mathrm{~m} \mathrm{~s}^{-1}$, there is no visible tearing of the

elastomer. However, the presence of elastomer damage is apparent in optical micrographs, increasing in severity with the impact velocity, as shown in Fig. 9. 


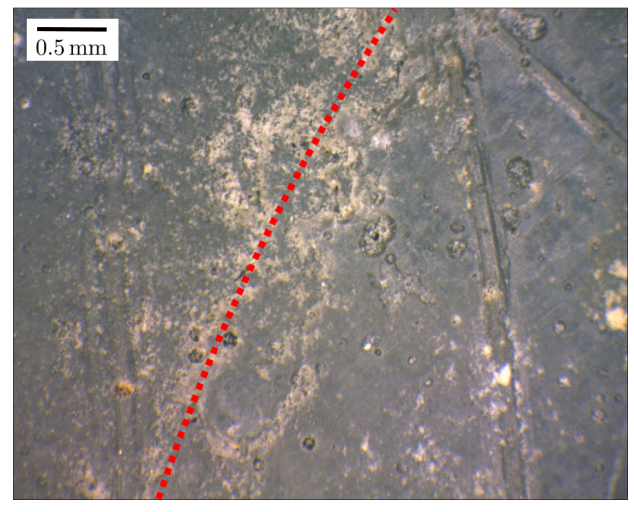

(a) $45 \mathrm{~m} \mathrm{~s}^{-1}$

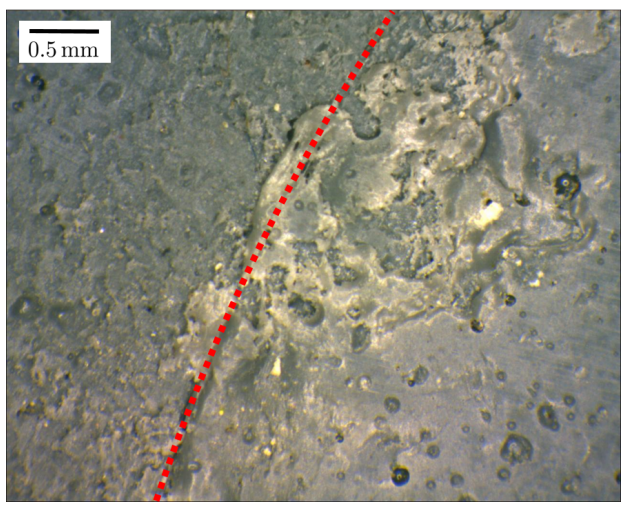

(b) $64 \mathrm{~m} \mathrm{~s}^{-1}$

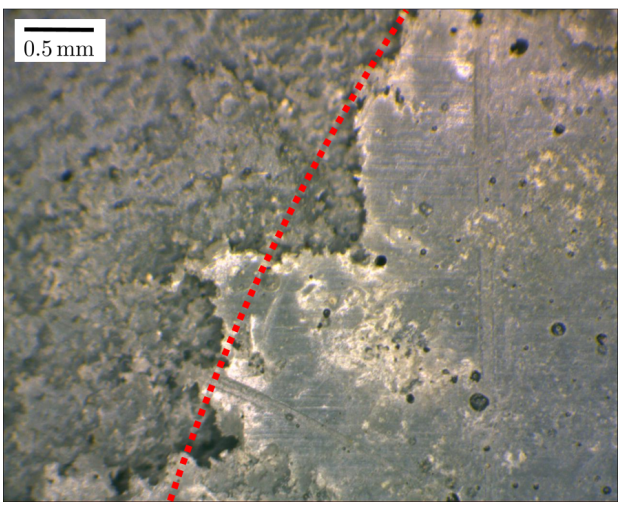

(c) $101 \mathrm{~m} \mathrm{~s}^{-1}$

Figure 9: Micrographs showing the distal face of the elastomer coating, at the edge of the impact site, for projectile velocities of 45,64 and $101 \mathrm{~m} \mathrm{~s}^{-1}$. The dotted line indicates the perimeter of the projectile contact patch.

A band of damaged material is evident around the perimeter of the projectile impact site. Voids form, which grow and coalesce - these are readily observed in the micrograph at $64 \mathrm{~m} \mathrm{~s}^{-1}$ (Fig. 9b). At higher impact velocities (above around $100 \mathrm{~m} \mathrm{~s}^{-1}$ ), there is evidence of ductile tearing around the perimeter of the impact site (Fig. 9c).

We find that the coated concrete cube is completely fragmented at an impact velocity of $142 \mathrm{~m} \mathrm{~s}^{-1}$. The elastomer fails around the perimeter of the projectile, forming a plug. The polymer plugs are recovered after the experiment, and found to have a diameter of around $14 \mathrm{~mm}$, which is about half that of the projectile. This indicates that the coating undergoes significant elastic straining prior to failure. The residual hole in the coating is, similarly, much less than the projectile diameter (Fig. 8b-c). Examination of the polymer coating 
in the vicinity of the hole shows a rough surface indicative of ductile tearing, accompanied by significant elastic contraction. This observation suggests that an impact-induced glass transition $[11,12]$ is not a dominant energy dissipation mechanism for these impact conditions and coating, even at the highest strain rates seen in our tests $\left(c .10^{4} \mathrm{~s}^{-1}\right)$. To explain this observation, the glass transition temperature of the polymer is measured using dynamic mechanical analysis (see Appendix B). Although the glass transition will shift to higher temperatures with increasing strain rate, it is found to be too low in this polymer to likely play a major role for the strain rates encountered in these experiments.

Probing the range of impact velocities between 100 and $142 \mathrm{~m} \mathrm{~s}^{-1}$, we observe that the projectile first fully penetrates, and is completely arrested by, the polymer coating at a speed of $124 \mathrm{~m} \mathrm{~s}^{-1}$. This case is shown in Fig. 7. The concrete exhibits damage immediately under the projectile and radial cracking on the impacted face of the cube, but remains otherwise intact. In this case we also observe the elastomer plug remains 'welded' to the face of the concrete cube after impact.

In summary, the concrete cube appears to be completely undamaged for impact velocities up to $100 \mathrm{~ms}^{-1}$ in its coated configuration. Severe concrete damage is observed in the uncoated cubes for impact velocities of $64 \mathrm{~m} \mathrm{~s}^{-1}$ and above. When coated, impact velocities in excess of $124 \mathrm{~m} \mathrm{~s}^{-1}$ are required to achieve a similar level of damage.

\section{FE model development}

\subsection{Concrete}

To gain a greater insight into the underlying protective mechanisms at play, a finite element (FE) model is developed using the code Abaqus/Explicit [21]. As a first step, it is necessary to obtain a concrete constitutive model that matches the behavior of the cast concrete used in the experimental study.

We choose the same Concrete Damaged Plasticity (CDP) model employed in [6] and [7], and which is available in Abaqus/Explicit [21]. The concrete is modelled as a homogeneous continuum that exhibits isotropic, damaged elasticity and isotropic, pressure-dependent plasticity. A continuum damage mechanics approach has been shown by many authors [24-28] to be appropriate for modelling concrete (and other quasi-brittle materials). We note that 
microstructure sensitivity of the localised impact damage of concrete is an important consideration, and one that requires further research. However, we can have confidence, from the experimental comparisons discussed subsequently, that the continuum model fidelity is sufficient for the effects we study here. The compressive behaviour is defined in terms of a uniaxial compressive stress, $\sigma_{c}$ vs. inelastic strain, $\tilde{\epsilon}_{c}^{i n}$ relationship according to the empirical relationships set out in the CEB-FIP Model Code [29]. The tensile response is defined in terms of the uniaxial tensile stress, $\sigma_{t} v s$. cracking displacement, $u_{t}^{c k}$, based on the relationship proposed by Hordijk [30]. Damage is captured by a degradation in elastic stiffness, quantified by the compressive and tensile damage parameters, $d_{c}$ and $d_{t}$ which can take values between zero (undamaged material) and one (fully damaged material). These damage parameters are defined to evolve as a function of inelastic strain, $\tilde{\epsilon}_{c}^{i n}$ and cracking displacement, $u_{t}^{c k}$, respectively, according to the relationship proposed by Birtel and Mark [31]. A table of the key user-defined parameters for implementation of this concrete model are presented in Appendix C. Further details are provided in [6] and [7].

For the concrete constitutive model, we scale the compressive, tensile and damage parameters to achieve a good match with the quasi-static, compressive stress-strain response presented in Fig. 2. The resulting numerical prediction is compared with the experimental curve in Fig. 2, illustrating that a good match is obtained.

\subsection{Elastomer}

The methodology used to obtain a constitutive model for the elastomer coating is as described in [6]. A number of material characterisation tests are performed on a sample of a commercially available, spray-on polyurea/polyurethane hybrid using an Instron screwdriven materials testing machine. A hyperelastic constitutive relationship is selected, fitted to the uniaxial tensile response up to a nominal strain, $\epsilon=1$, using data measured at a nominal strain rate, $\dot{\epsilon}=10^{-3} \mathrm{~s}^{-1}$. The Yeoh strain energy potential is chosen as it is deemed to provide the best fit to experimental measurements. Viscoelasticity is incorporated via a Prony series for similar materials, obtained from the literature [32]. The polymer has a density of $1.1 \mathrm{Mg} \mathrm{m}^{-3}$, and is assumed to be approximately incompressible (a Poisson's ratio $\nu=0.475$ is used, the maximum permitted in the FE analysis [21]). 
To assess the accuracy of the model, quasi-static compression tests are performed on discs cut from a sample of the spray-on elastomer coating. An elastomer disc, $25.9 \mathrm{~mm}$ in diameter and $3.68 \mathrm{~mm}$ in thickness is compressed between steel platens at a nominal strain rate, $\dot{\epsilon}=10^{-3} \mathrm{~s}^{-1}$ using an Instron screw driven test machine. The specimen is loaded to a nominal strain of approximately $\epsilon=0.6$, before unloading. This test is simulated in Abaqus/Explicit, using an axisymmetric model, and assuming frictionless contact with rigid platens. The resulting force-displacement response is shown in Fig. 10.

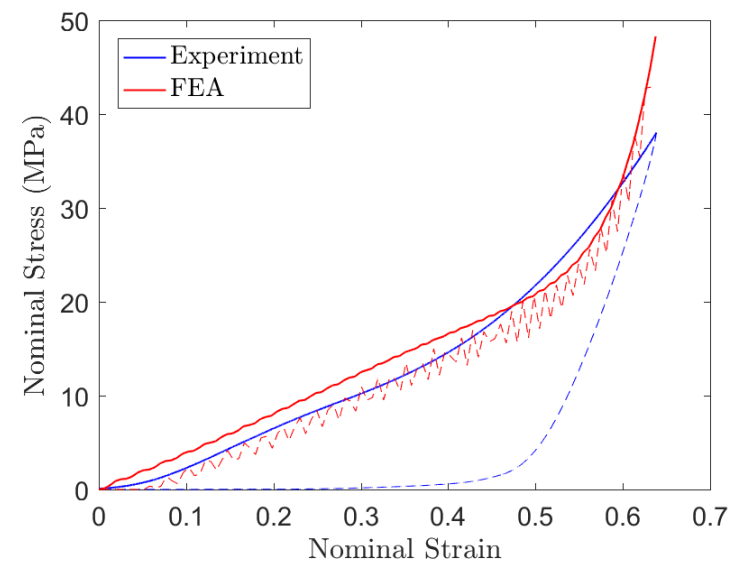

Figure 10: Quasi-static compression of the elastomer, at $\dot{\epsilon}=10^{-3} \mathrm{~s}^{-1}$. Unloading is shown as a dotted line.

We obtain very good agreement for the loading portion of the curve though we fail to capture the pronounced hysteresis loop upon unloading. This limitation for the Prony series representation of viscoelastic behaviour has previously been reported in the literature. We therefore note this limitation as we proceed.

To further validate the elastomer model, we perform both quasi-static (at a strain rate of $10^{-3} \mathrm{~s}^{-1}$ ) and high strain rate $\left(\right.$ at $10^{2} \mathrm{~s}^{-1}$ ) uniaxial tension and shear punch experiments. Again, frictionless contact is assumed at elastomer/steel interfaces. Determining the role of interface friction in these tests, and those described subsequently, is complex, and further investigation is required to understand its importance. For the purposes of this particular study, the interface friction assumptions in the numerical model are chosen based on best fit with a specific set of experimental results. However, we note that further validation would be required to assess their accuracy under a wider range of loading conditions and strain rates. The results are presented in Appendix D which show that the viscoelastic model captures 
the strain rate dependence of the elastomer well.

\section{Quasi-static indentation}

Before proceeding to simulations of the impact tests, we first assess the predictive capabilities of the model for the quasi-static indentation response of uncoated and coated concrete cubes. This allows a clearer comparison with experimental measurements, to help interrogate modelling decisions.

\subsection{Uncoated concrete}

A quasi-static indentation test is performed on a $100 \mathrm{~mm}$ concrete cube. A circular cylindrical steel indenter of diameter $28.5 \mathrm{~mm}$ (identical to the projectiles used in the impact tests) is pressed into the surface of the concrete cube using an Instron screw driven test

machine, at a speed of $1 \times 10^{-4} \mathrm{~m} \mathrm{~s}^{-1}$. Indenter force was measured using the test machine load cell. Indentation depth was measured using cross head displacement, adjusted for compliance using a laser extensometer.

The same test is simulated in Abaqus/Explicit. The concrete block is modelled axisymmetrically, with a radius of $50 \mathrm{~mm}$ and a height of $100 \mathrm{~mm}$. A mesh size of $0.5 \mathrm{~mm}$ is used for a domain of size $40 \mathrm{~mm}$ around the contact patch. This is then graded to a mesh size of $5 \mathrm{~mm}$ at the edge of the block. ALE adaptive meshing is used in the concrete region directly under the indenter in an effort to maintain a high quality mesh throughout the analysis. The indenter is modelled as an axisymmetric discrete rigid part with a small corner radius of $1.5 \mathrm{~mm}$ added to prevent a stress singularity at the indenter perimeter. Frictionless contact conditions are prescribed between the indenter and the concrete.

The chosen mesh and corner radius combination is a result of a detailed sensitivity study. It was found that while a coarse mesh was insufficient to accurately capture indentation behaviour, an extremely fine mesh resulted in extensive, unrealistic crack branching (indicated by the distribution of damaged elements). Further, we found the indentation response was relatively sensitive to the chosen indenter corner radius. Therefore, it was necessary to identify the smallest value (i.e. closest to a perfectly sharp edge) that could be adequately resolved by the FE mesh, while avoiding excessively small elements (for the reasons out- 
lined above). To help confirm the final choice of corner radius and mesh, we compare the predicted distribution of stress under the indenter, with the existing theoretical solution for a flat-ended circular cylinder with a sharp corner, indenting an elastic half space. The results are presented in Appendix E and show good agreement between the FE model and the theoretical result.

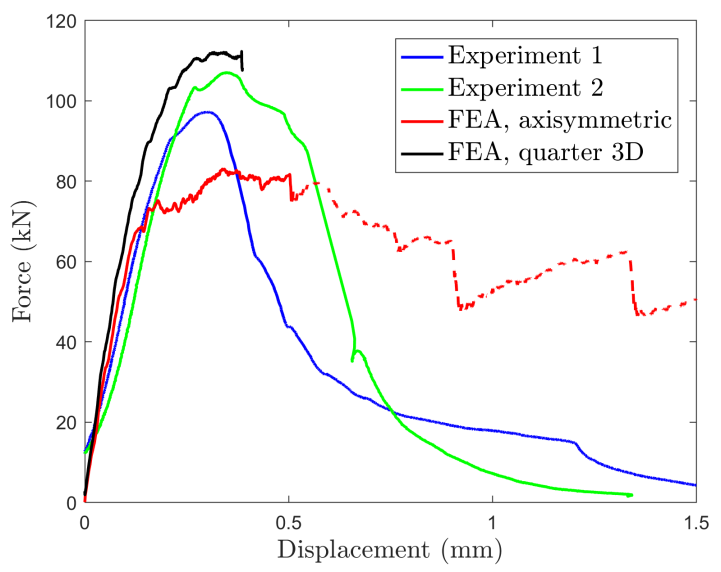

Figure 11: Quasi-static indenter force-displacement response for uncoated concrete. For the FE results, the dotted line indicates the prediction after the first significant drop in load, at which point extensive damage has occurred.

Comparison between the FE predictions and experiment are presented in Fig. 11. First, we observe that our FE model provides an accurate prediction of the indentation stiffness which appears to be experimentally repeatable. However, we notice some scatter in the yield point obtained experimentally and find that our FE model underpredicts this. Inherent material variability may be a factor in this discrepancy, including sensitivity to local effects such as coarse aggregate distribution near the surface and local indenter geometry. The indentation yield point might also be sensitive to the details of the indenter corner radius, in both the experiment and model, and the effect this has on the local stress and stress triaxiality. Furthermore, the stress triaxiality dependence of the concrete constitutive model may lose fidelity under the complex stress state under the indenter.

There is also some discrepancy between model and experiment in terms of post-peak response. The experiments show strong softening after the onset of damage, with complete failure of the block occurring at indenter displacements of approximately $1-1.5 \mathrm{~mm}$. The FE 
prediction, however, gives a more progressive propagation of damage, that continues after the first significant load drop. We note that damaged elements are not deleted in the FE model. Also, the axisymmetric model will not permit radial cracks to develop. These factors may alter the predicted mode of global failure of the block. Hence, the FE predictions should be interpreted with caution once damage development is extensive (as indicated by the dotted line in Fig. 11). Also plotted on Fig. 11 is the prediction obtained using a 3D quarter model. Once more, the indentation stiffness is accurately predicted and in this case, we also achieve a good match to the measured peak strength. The post-peak behaviour is not captured as the model suffers from excessive element distortions due to the nature of the loading. For this reason, coupled with the large computational cost, we choose to proceed with the axisymmetric approach. The axisymmetric model will not capture 3D failure mechanisms such as radial cracking. However, we observe that the key damage phenomena occur at earlier timescales compared to radial cracking, and thus a full 3D model is not critical to our subsequent analysis of damage initiation.

\subsection{Coated concrete}

We consider next the quasi-static indentation of a $100 \mathrm{~mm}$ concrete cube, coated on its indented face with a $4 \mathrm{~mm}$ thick elastomer layer. The experimental technique is as described in Section 4.1, above. Similarly, an axisymmetric FE model is used for the concrete and polymer coating, with the constitutive behaviour of each material as defined in Section 3. The finite element mesh for the concrete part is identical to that defined in Section 4.1. The polymer is discretised using an identical mesh size to the concrete: $0.5 \mathrm{~mm}$ elements are used over a $40 \mathrm{~mm}$ radius in the vicinity of the contact patch, transitioning to $5 \mathrm{~mm}$ at the edges.

Frictionless contact is prescribed between the indenter and the elastomer. Two contact conditions are examined between the elastomer and concrete cube: frictionless and Coulomb friction with a friction coefficient $-\mu=0.8$ (a reasonable value for concrete/rubber interactions [34]). A plot of the indenter force-displacement response for each case is compared with the experimental measurement in Fig. 12. 


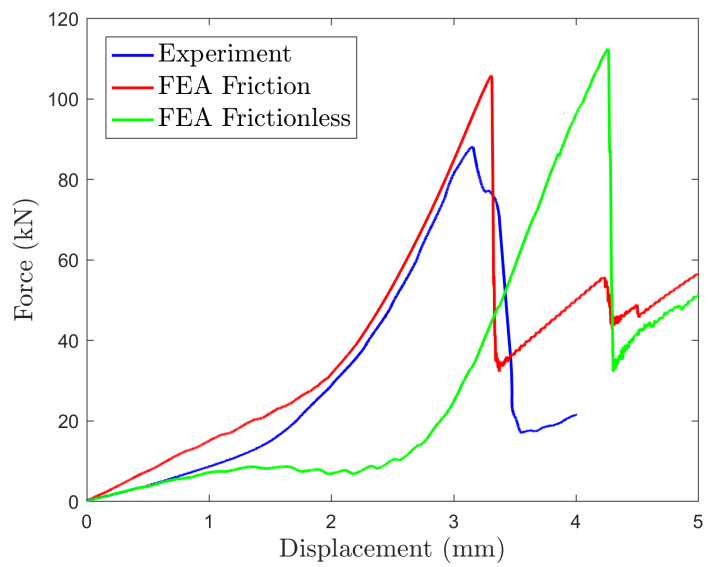

Figure 12: Comparison between experiment and two FE models of the quasi-static indenter forcedisplacement response for coated concrete. One FE model includes frictionless contact between the elastomer layer and concrete, while the other assumes Coulomb friction with a friction coefficient $-\mu=0.8$.

As noted for the uncoated concrete, the FE does not exactly predict the peak force, and there is some discrepancy after the first load drop. But, overall, the FE predicts the indentation response well, as long as frictional effects between the elastomer and concrete are accounted for. This interface condition will therefore be assumed in all subsequent calculations.

\section{Impact indentation}

Satisfied with the agreement obtained between the FE models and the quasi-static indentation experiments, we proceed to model the impact experiments described in Section 2. We again use an axisymmetric representation of the concrete, polymer coating and projectile in the FE analysis. The modelling parameters are identical to those described in Section 4. The projectile mass is $0.1 \mathrm{~kg}$, and it is assigned an initial velocity in the simulations to match the experimental values, obtained from high speed photography. Rigid body motion of the concrete target is prevented by constraining the vertical displacement of the distal face.

\subsection{Uncoated concrete}

First, we consider the uncoated concrete cases. The projectile velocity-time histories predicted by the model are compared in Fig. 13 with experimental measurements, obtained from high speed photography. 


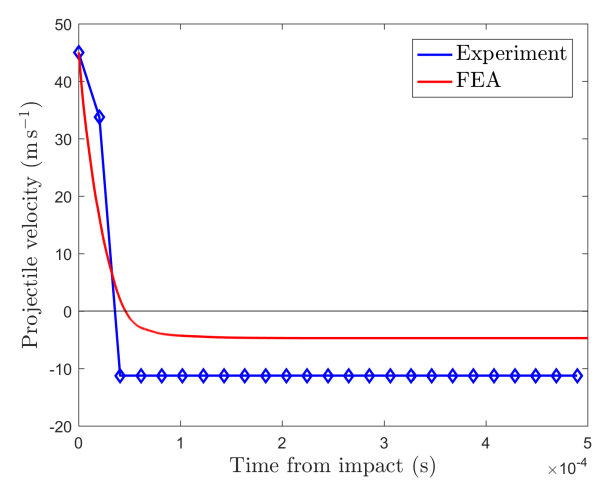

(a) $45 \mathrm{~m} \mathrm{~s}^{-1}$

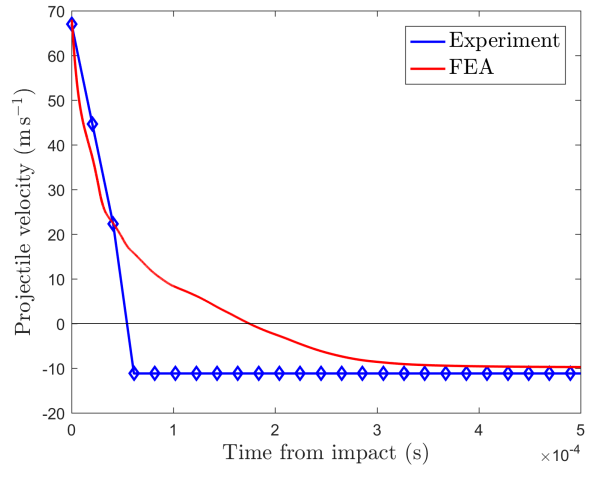

(b) $68 \mathrm{~m} \mathrm{~s}^{-1}$

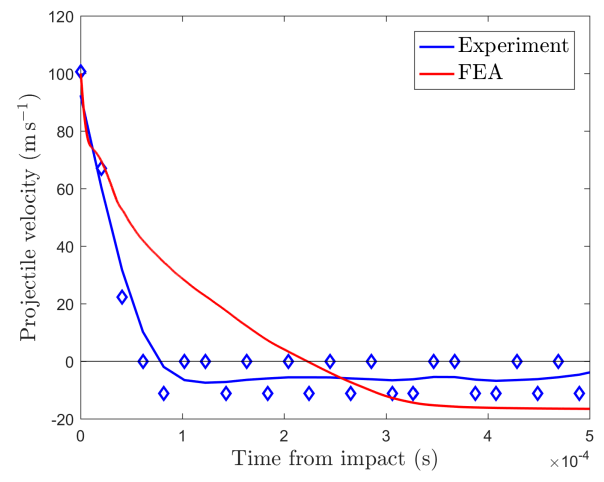

(c) $100 \mathrm{~m} \mathrm{~s}^{-1}$

Figure 13: Projectile velocity-time history obtained from the impact experiments and the FE analysis, for the uncoated concrete specimens.

The FE model provides reasonably accurate predictions of the projectile velocity-time histories across the range of impact speeds considered, both for the loading portion of the response (up to zero projectile velocity) and also for the projectile rebound velocity. We note, however, that the ability of the model to accurately capture the shape of the velocity-time curve diminishes with higher projectile impact speeds. In these cases, damage development is extensive, and for the reasons highlighted in Section 4.1, the FE predictions should be interpreted with caution.

Figure 14 presents the FE model predictions for the compressive damage experienced by the uncoated concrete targets for the three projectile impact speeds considered. 


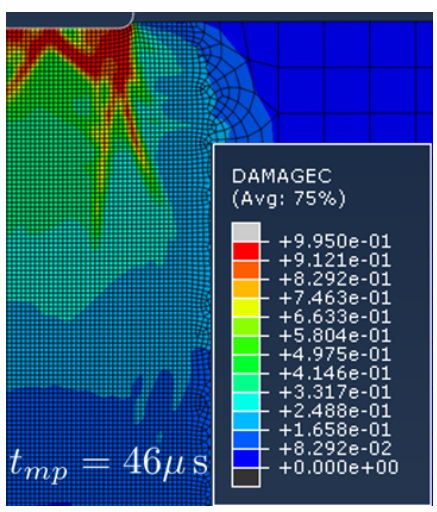

(a) $45 \mathrm{~m} \mathrm{~s}^{-1}$

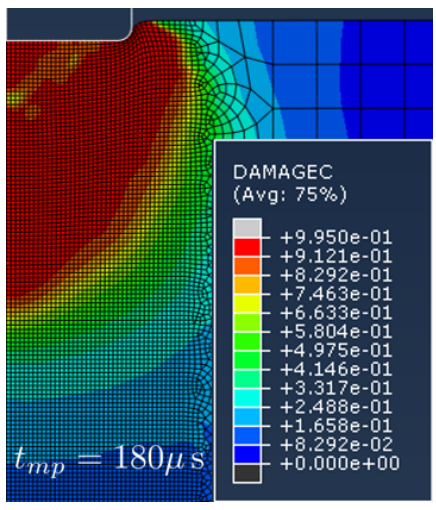

(b) $68 \mathrm{~m} \mathrm{~s}^{-1}$

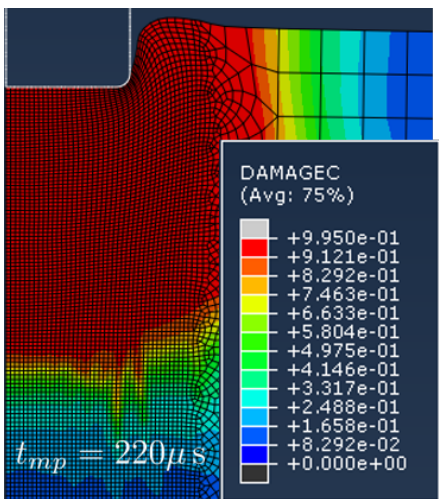

(c) $100 \mathrm{~m} \mathrm{~s}^{-1}$

Figure 14: Contours of the compressive damage parameter, $d_{c}$ for the impact simulations of uncoated concrete cubes at projectile impact velocities of $45 \mathrm{~m} \mathrm{~s}^{-1}, 68 \mathrm{~m} \mathrm{~s}^{-1}$ and $100 \mathrm{~m} \mathrm{~s}^{-1} . d_{c}=0$ represents completely undamaged material and $d_{c}=1$ is completely damaged. Images taken at the time of maximum indenter penetration, $t_{m p}$.

As was observed in the experiments (Figs. 4 - 6), the level of damage experienced by the concrete target increases with increasing projectile impact speed. For impact speeds of $68 \mathrm{~m} \mathrm{~s}^{-1}$ and $100 \mathrm{~ms}^{-1}$, a significant amount of damage is predicted (i.e. $d_{c}=1$ ) which agrees well with experimental observations. Figure 15 shows the progress of damage for the $45 \mathrm{~m} \mathrm{~s}^{-1}$ impact case, illustrating that for higher impact speeds the damage continues to propagate after the point of maximum projectile penetration, though not significantly.
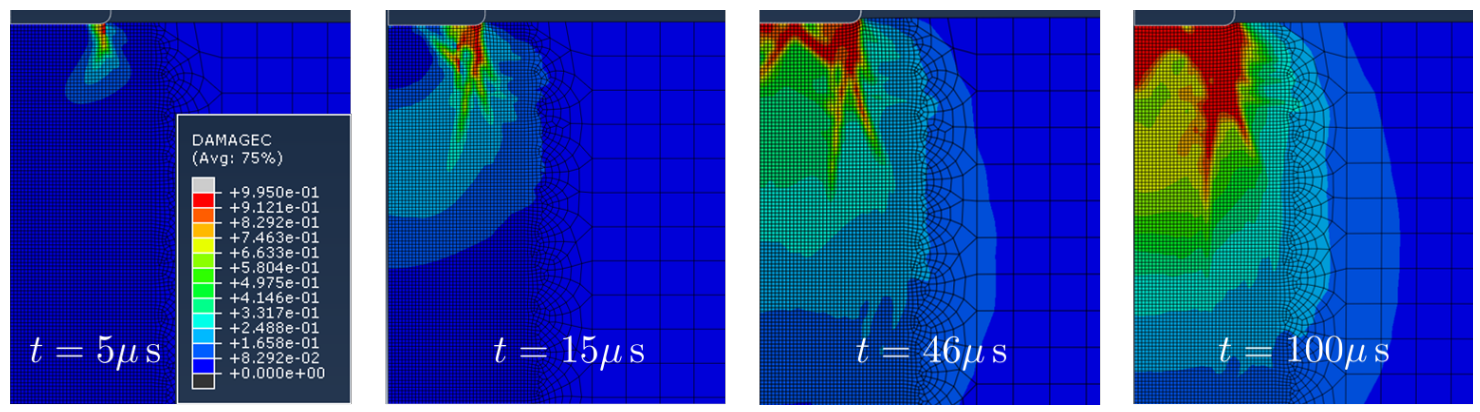

Figure 15: Progress of damage for the impact indentation of an uncoated cube with an initial projectile speed of $45 \mathrm{~m} \mathrm{~s}^{-1}$. Contours of the compressive damage parameter, $d_{c}$ where $d_{c}=0$ represents completely undamaged material and $d_{c}=1$ is completely damaged. The image at $t=46 \mu \mathrm{s}$ corresponds to the time of maximum indenter penetration.

Complete fragmentation of the block, observed in the experiments for a projectile impact 
speed of $100 \mathrm{~m} \mathrm{~s}^{-1}$ (Fig. 6), cannot be predicted by the FE model given the lack of element deletion. However, this is likely to occur in the later stages of projectile penetration. The FE is therefore best used to predict the earlier stages of damage initiation and development in these cases.

\subsection{Coated concrete}

Next, the coated concrete targets are considered. Figure 16 compares the FE predictions for the projectile velocity-time histories with those measured using high speed photography during the impact experiments. The FE modelling parameters are again identical to those described in Section 4, with a coefficient of friction, $\mu=0.8$ between the polymer and concrete layers and frictionless contact is assumed at polymer/steel interfaces.

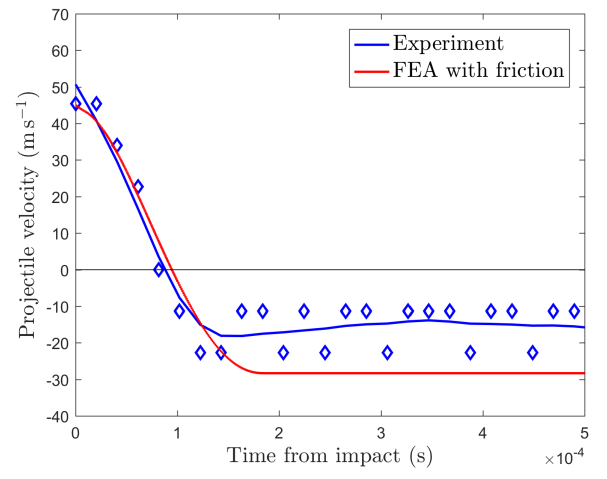

(a) $45 \mathrm{~m} \mathrm{~s}^{-1}$

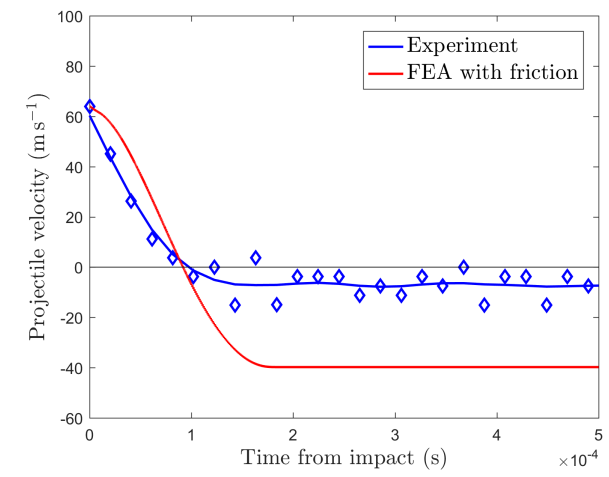

(b) $64 \mathrm{~m} \mathrm{~s}^{-1}$

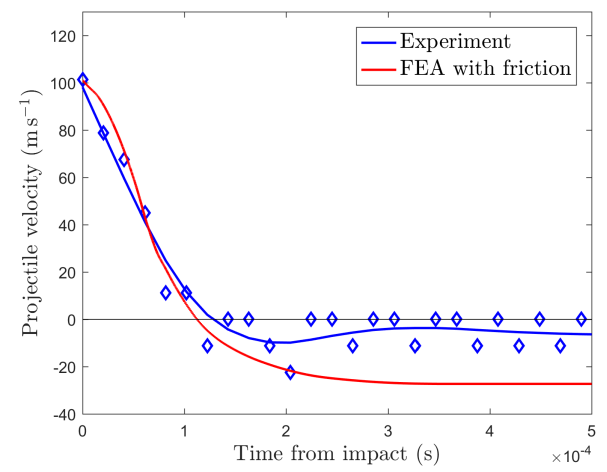

(c) $101 \mathrm{~m} \mathrm{~s}^{-1}$

Figure 16: Projectile velocity-time history obtained from the impact experiments and the $\mathrm{FE}$ analysis for coated concrete specimens. The FE model considers a friction coefficient, $\mu=0.8$ between the elastomer and concrete. 
The FE model provides excellent agreement with the experimental measurements for the loading portion of the response, up to the point of maximum projectile penetration (i.e. zero projectile velocity). Beyond this point, the FE model overestimates the projectile rebound velocities. As was noted in Section 3.2, the elastomer constitutive model fails to capture well the measured hysteresis upon unloading, which may account for this discrepancy. This is supported by a supplementary investigation of the sensitivity to the viscoelastic model, described in Appendix F.

Figure 17 illustrates the compressive damage patterns predicted by the FE model for the coated concrete cubes, at the three projectile impact speeds considered.

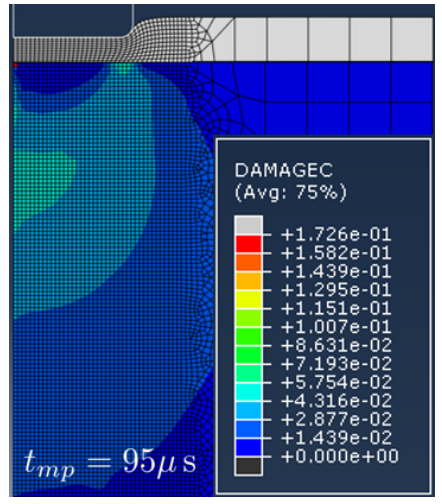

(a) $45 \mathrm{~m} \mathrm{~s}^{-1}$

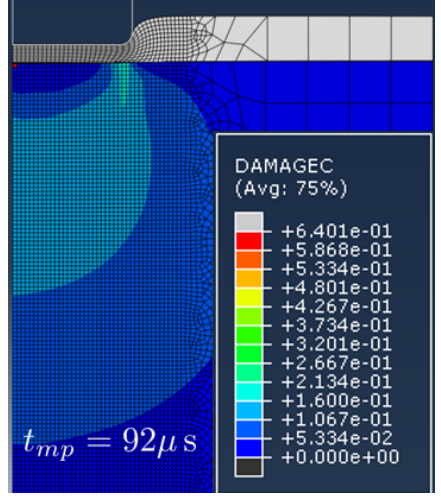

(b) $64 \mathrm{~m} \mathrm{~s}^{-1}$

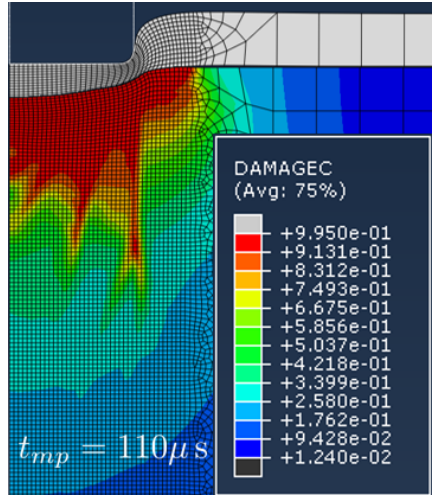

(c) $101 \mathrm{~m} \mathrm{~s}^{-1}$

Figure 17: Contours of the compressive damage parameter, $d_{c}$ for the impact simulations of coated concrete cubes at projectile impact velocities of $45 \mathrm{~m} \mathrm{~s}^{-1}, 64 \mathrm{~m} \mathrm{~s}^{-1}$ and $101 \mathrm{~m} \mathrm{~s}^{-1} . d_{c}=0$ represents completely undamaged material and $d_{c}=1$ is completely damaged. Images taken at the time of maximum indenter penetration, $t_{m p}$.

No severe $\left(d_{c}=1\right)$ concrete damage is predicted for projectile impact speeds of $45 \mathrm{~m} \mathrm{~s}^{-1}$ and $64 \mathrm{~m} \mathrm{~s}^{-1}$, though significant straining of the elastomer under the corner of the projectile is observed. These predictions agree well with the experimental observations in Figs. 4, 5 and 9 , which show that the concrete exhibits no visible damage, while the elastomer coating undergoes minor damage at the perimeter of the contact patch.

The FE model predicts that severe compressive damage occurs to a depth of around $10 \mathrm{~mm}$, for the coated cube impacted at $101 \mathrm{~ms}^{-1}$. This is in contrast to the apparently undamaged concrete specimen recovered from the experiment (Fig. 6). This discrepancy 
could be due to a number of factors. First, no strain rate dependence is accounted for in the concrete constitutive model which could influence the concrete strength at these higher projectile impact speeds. Furthermore, the elastomer constitutive model does not include a failure criterion. Thus the elastomer tearing observed in the experiment (Fig. 9c) is not predicted explicitly. This would provide an additional dissipative mechanism, absent from the current analysis. Nonetheless, the significant protective effect of the coating is captured by the model. We therefore proceed to interrogate the protective mechanisms in more detail.

\section{Discussion: influence of coating on impact damage initiation}

In the following, we use the $\mathrm{FE}$ model to gain an insight into how the elastomer is achieving its damage mitigating effect. Focusing attention on the early time steps of indenter penetration, we interrogate how the coating influences damage initiation in the concrete target.

Figures 18 and 19 show the distribution of the concrete damage parameter, $d_{c}$ taken at a time, $t_{d i}$ corresponding to the point of damage initiation for uncoated and coated concrete cubes, respectively for three impact speeds. Note that $d_{c}=0$ represents an undamaged material, and $d_{c}=1$ is completely damaged. We define the 'initiation' of damage to occur when a damage parameter $d_{c}>0.9$ is calculated to a depth of at least $1 \mathrm{~mm}$ in the concrete. Values of the time after impact at which damage initiates, $t_{d i}$, and the depth of projectile penetration at this time, $\delta_{d i}$, are also quoted in the Figures. 


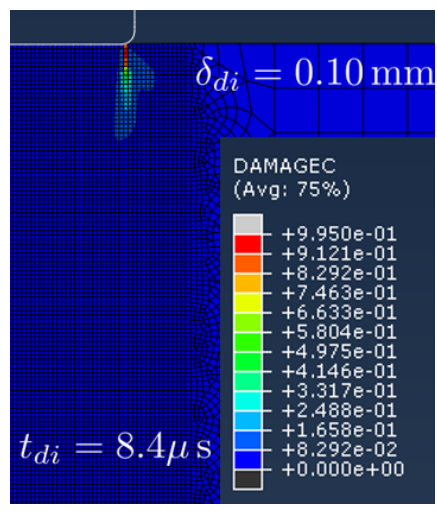

(a) $15 \mathrm{~m} \mathrm{~s}^{-1}$

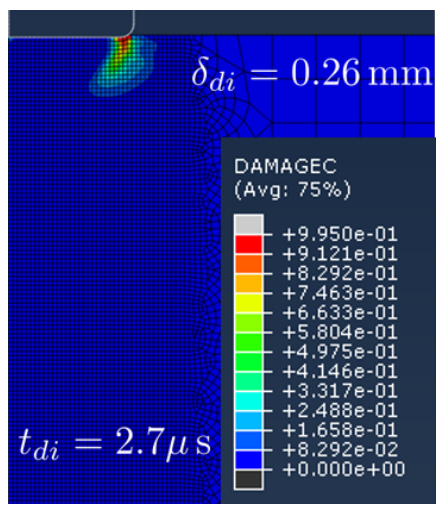

(b) $101 \mathrm{~m} \mathrm{~s}^{-1}$

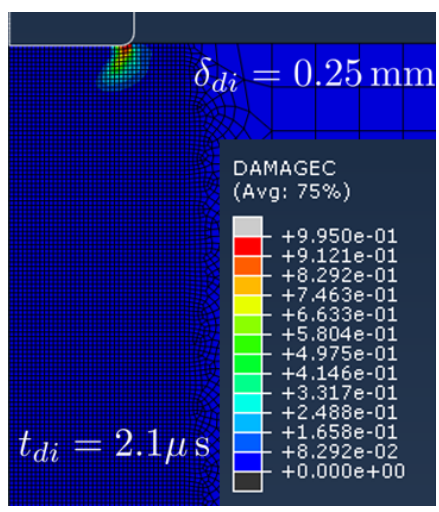

(c) $124 \mathrm{~m} \mathrm{~s}^{-1}$

Figure 18: Plotting contours of the compressive damage parameter, $d_{c}$ for the impact indentation simulations of uncoated concrete targets at impact velocities of $15 \mathrm{~m} \mathrm{~s}^{-1}, 101 \mathrm{~m} \mathrm{~s}^{-1}$ and $124 \mathrm{~m} \mathrm{~s}^{-1}$. Images are shown at the point of damage initiation, as defined in the main text.

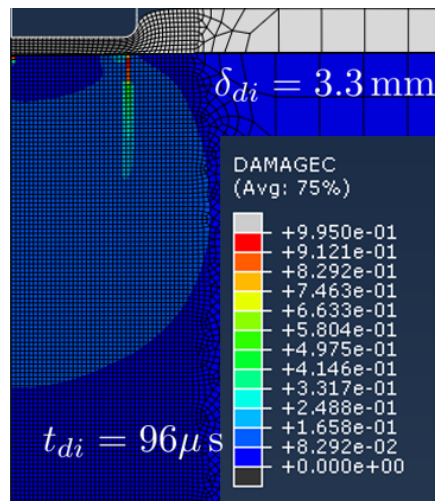

(a) $63 \mathrm{~m} \mathrm{~s}^{-1}$

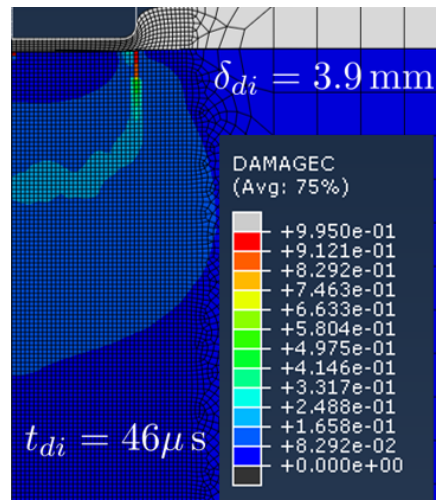

(b) $101 \mathrm{~m} \mathrm{~s}^{-1}$

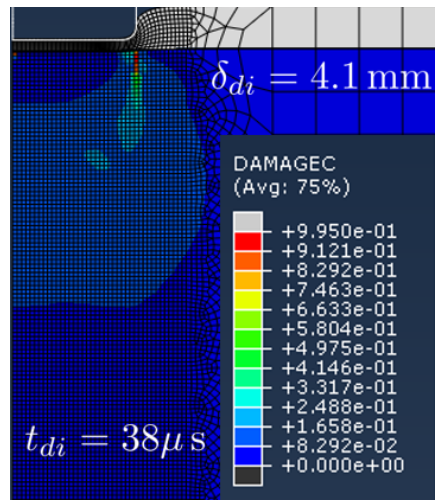

(c) $124 \mathrm{~m} \mathrm{~s}^{-1}$

Figure 19: Plotting contours of the compressive damage parameter, $d_{c}$ for the impact indentation simulations of coated concrete targets, coated with a $5 \mathrm{~mm}$ elastomer layer, at impact velocities of $63 \mathrm{~m} \mathrm{~s}^{-1}, 101 \mathrm{~m} \mathrm{~s}^{-1}$ and $124 \mathrm{~m} \mathrm{~s}^{-1}$. Images are shown at the point of damage initiation, as defined in the main text.

Using this definition of damage initiation, the minimum impact velocity at which this criterion is met can be found. This occurs at an impact speed of $15 \mathrm{~m} \mathrm{~s}^{-1}$ for the uncoated concrete (Fig. 18a) and $63 \mathrm{~m} \mathrm{~s}^{-1}$ for the coated concrete (Fig. 19a).

Comparing these two cases, three key effects of the coating are apparent. (i) The time taken to initiate concrete damage is at least an order of magnitude larger in the coated case. (ii) The projectile has indented the coating by a large fraction of its thickness at the 
onset of concrete damage. (iii) The critical location for concrete damage remains at the projectile perimeter, but with the coating in place, there is a more diffuse distribution of concrete damage when the initiation criterion is met. (i) and (ii) indicate that a polymer coating reduces projectile decelerations and therefore contact stresses, for a given impact scenario. Table 1 presents the average projectile decelerations, calculated from the projectile velocity-time histories obtained from the high speed photography (plotted in Figs. 13 and 16). Taking the average projectile deceleration to be indicative of the average contact pressure, we infer that the coating does indeed serve to reduce the contact stresses. The FE models also support the conclusion that the projectile average decelerations are reduced by between $40-60 \%$ with the addition of the polymer coating.

\begin{tabular}{|l|cc|cc|cc|}
\hline Impact speed & \multicolumn{2}{|c|}{$45 \mathrm{~m} \mathrm{~s}^{-1}$} & \multicolumn{2}{c|}{$\approx 65 \mathrm{~m} \mathrm{~s}^{-1}$} & \multicolumn{2}{c|}{$\approx 100 \mathrm{~m} \mathrm{~s}^{-1}$} \\
\hline & $\mathrm{FE}$ & Experiment & $\mathrm{FE}$ & Experiment & $\mathrm{FE}$ & Experiment \\
Uncoated & $0.98 \times 10^{6}$ & $1.25 \times 10^{6}$ & $1.14 \times 10^{6 *}$ & $1.26 \times 10^{6}$ & $2.18 \times 10^{6 *}$ & $1.28 \times 10^{6}$ \\
Coated & $0.47 \times 10^{6}$ & $0.5 \times 10^{6}$ & $0.7 \times 10^{6}$ & $0.65 \times 10^{6}$ & $0.92 \times 10^{6}$ & $0.78 \times 10^{6}$ \\
\hline
\end{tabular}

Table 1: Average projectile decelerations (up to maximum projectile penetration) in $\mathrm{ms}^{-2}$ measured from Figs. 13 and 16. For cases marked with an asterisk, average deceleration is measured up to the time that FE predictions depart from experimental measurements as a result of severe concrete damage. Refer to Appendix A for exact impact velocities for each case.

Furthermore, observation (iii) indicates delocalisation of concrete damage. In combination, these effects appear to explain the protective benefit of the coating. Similar trends are observed at higher velocities (Figs. 18b, c and 19b, c) where the elastomer also acts to significantly delay the onset of damage initiation, and leads to a more diffusive pattern of damage. Note that at these higher impact speeds, the projectile is still in motion at the instant of damage initiation shown in Figs. 18 and 19.

This investigation identifies the protective effect of a polymer coating, for a particular combination of polymer type, coating thickness, concrete strength and projectile geometry. Further work is required to identify how sensitive the coating performance and protective mechanisms are to variations in these parameters, and hence how to optimise the coating design. 


\section{Conclusions}

An experimental and numerical investigation has been conducted to assess the impact mitigating capabilities of a typical spray-on elastomer coating, applied to the impacted face of a concrete target. The FE model is used to interrogate how the elastomer influences damage initiation in the concrete substrate, for a range of impact speeds. The following conclusions are established:

- An elastomer coating significantly reduces impact damage in the concrete over the full range of projectile velocities tested, c. $45-150 \mathrm{~m} \mathrm{~s}^{-1}$. For the particular geometry considered, an uncoated concrete cube experiences severe damage at a projectile velocity of c. $60 \mathrm{~m} \mathrm{~s}^{-1}$ whereas in its coated configuration, velocities of c. $120 \mathrm{~m} \mathrm{~s}^{-1}$ are required to achieve a similar level of damage.

- The elastomer coating remains intact until impacted at a speed of c. $120 \mathrm{~m} \mathrm{~s}^{-1}$. Damage remains local to the perimeter of the projectile, where there is evidence of ductile tearing. At higher impact velocities, a polymer plug is detached. The plug and corresponding hole in the coating undergo significant elastic contraction after projectile penetration.

- A finite element model in Abaqus/Explicit [21] is validated as an effective analysis tool for impact indentation of uncoated and coated concrete cubes under certain conditions. We deem our model valid at early time steps, before the concrete becomes severely damaged. Further, for the coated cases, we limit our experimental comparisons up to the point of maximum indenter penetration to avoid modelling inaccuracies associated with the unloading phase.

- The finite element analysis indicates that for this projectile geometry and coating thickness, the elastomer acts to alter damage initiation in the concrete. The time taken for damage to initiate is increased by an order of magnitude, and occurs after significant polymer indentation. The spatial distribution of concrete damage is also affected, with damage delocalised by the coating. 


\section{Acknowledgements}

The authors are grateful to the George and Lillian Schiff Foundation of the University of Cambridge for financial support. 


\section{Appendix A. Experimental testing: further details}

Tables A.2 and A.3 present the impact velocities (measured using high speed photography) and the measured average elastomer thickness for each of the uncoated and coated impact tests, respectively.

\begin{tabular}{||cccc||}
\hline Uncoated Tests & 1 & 2 & 3 \\
\hline \hline Impact velocity $\left(\mathrm{m} \mathrm{s}^{-1}\right)$ & 45 & 68 & 100 \\
\hline Elastomer thickness $(\mathrm{mm})$ & 0 & 0 & 0 \\
\hline
\end{tabular}

Table A.2: Measured experimental parameters for the uncoated specimens.

\begin{tabular}{||cccccc||}
\hline Coated Tests & 1 & 2 & 3 & 4 & 5 \\
\hline \hline Impact velocity $\left(\mathrm{m} \mathrm{s}^{-1}\right)$ & 45 & 64 & 101 & 124 & 142 \\
\hline Elastomer thickness $(\mathrm{mm})$ & 5.53 & 5.35 & 6.02 & 5.21 & 5.36 \\
\hline
\end{tabular}

Table A.3: Measured experimental parameters for the coated specimens.

\section{Appendix B. Dynamic mechanical analysis of elastomer}

Figure B.20 presents measurements of the temperature dependence of the viscoelastic properties of the elastomer coating, obtained using a dynamic mechanical analyser (DMA). The properties were measured in bending mode at a frequency of $1 \mathrm{~Hz}$, using a clamped cantilever beam of length, $12.5 \mathrm{~mm}$, width, $10 \mathrm{~mm}$ and thickness, $5.8 \mathrm{~mm}$. The elastomer exhibits only one distinct peak in loss modulus, at approximately $-35^{\circ} \mathrm{C}$, corresponding to the glass transition temperature $\left(T_{g}\right)$. This is accompanied by a significant drop in storage modulus around this temperature. 


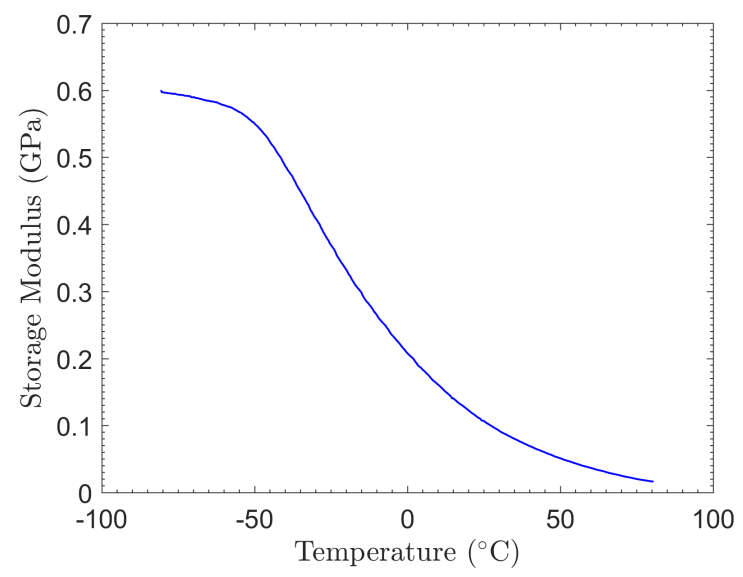

(a) Storage modulus

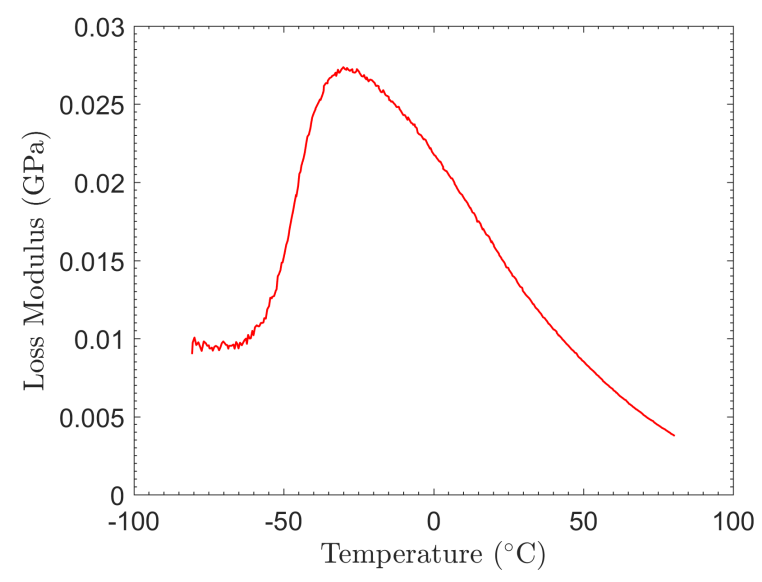

(b) Loss modulus

Figure B.20: Dynamic mechanical analysis results for the elastomer (in cantilever bending mode) at a frequency $1 \mathrm{~Hz}$ and at a heating rate of $5^{\circ} \mathrm{C}$ per minute.

For the test specimen geometry, the test frequency and displacement amplitude $(0.02 \mathrm{~mm})$ correspond to a strain rate of approximately $2 \times 10^{-3} \mathrm{~s}^{-1}$. According to Yi et al. [36], we can expect a $4-5^{\circ} \mathrm{C}$ shift in $T_{g}$ per decade increase in strain rate. Thus, we are unlikely to observe an impact induced glass transition up to the maximum strain rates seen in our impact tests, which is of the order $10^{4} \mathrm{~s}^{-1}$. However, the shift may be sufficient for a rise in loss modulus to contribute to energy dissipation at these higher rates. 


\section{Appendix C. Concrete constitutive model: further details}

Table C.4 presents a summary of the key parameters required to define the uniaxial compressive and tensile responses, the yield surface and the flow rule in the Concrete Damaged Plasticity model in Abaqus/Explicit. For further details, refer to [6, 21].

\begin{tabular}{||ccccc||}
\hline Compressive strength & Tensile strength & Young's modulus, $E$ & $\nu$ & $\rho$ \\
\hline $47 \mathrm{MPa}$ & $5 \mathrm{MPa}$ & $28.3 \mathrm{GPa}$ & 0.2 & $2550 \mathrm{~kg} \mathrm{~m}^{-3}$ \\
\hline \hline Dilation angle, $\psi$ & Eccentricity, $\epsilon$ & $f_{b 0} / f_{c 0}$ & $K_{c}$ & viscosity parameter \\
\hline $36^{\circ}$ & 0.1 & 1.16 & 0.667 & 0 \\
\hline
\end{tabular}

Table C.4: User-defined parameters required to define the Concrete Damaged Plasticity model in Abaqus/Explicit.

\section{Appendix D. Elastomer constitutive model: further validation}

To provide further validation of the chosen elastomer constitutive model, uniaxial tension and shear punch tests were performed and compared with the FE predictions. For both configurations, an Instron screw-driven materials testing machine was used to achieve quasistatic strain rates, of the order $10^{-3} \mathrm{~s}^{-1}$ while a servo-hydraulic materials testing machine was employed to achieve higher strain rates, up to $10^{2} \mathrm{~s}^{-1}$. Further details on these experimental tests are provided in [6].

In Fig. D.21, the experimental results are compared with the predictions obtained from FEA, using the elastomer constitutive model described in Section 3.2. No failure criterion was included in the model so failure stresses and strains are not comparable. 


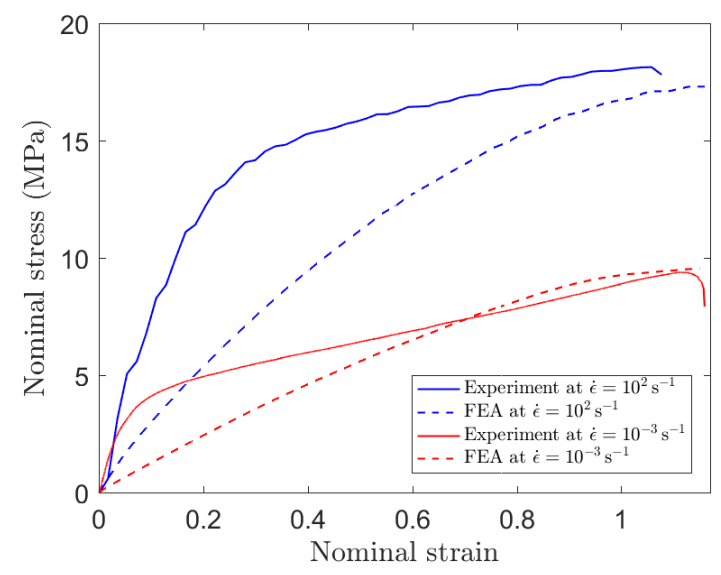

(a) Uniaxial tension

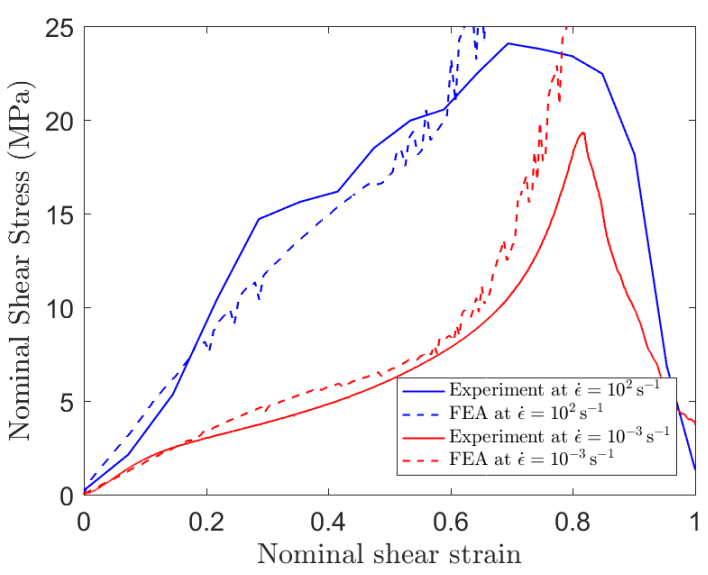

(b) Shear punch

Figure D.21: Comparison between experimental results and those obtained via FEA. Uniaxial tension and shear punch results are compared for strain rates, $\dot{\epsilon}=10^{-3} \mathrm{~s}^{-1}$ and $\dot{\epsilon}=10^{2} \mathrm{~s}^{-1}$.

Examining the uniaxial tension response in Fig. D.21a, reasonable agreement is achieved for the stresses at larger strains and we observe that the viscoelastic model captures the strain rate dependence well. However, the FE model underpredicts the initial modulus, failing to capture the precise shape of the tensile response curve. The initial stiffness is predicted more accurately for the shear punch test, in Fig. D.21b and once more, the strain rate dependence is captured well. The deformation of the coating in the projectile impact experiments is expected to be more dependent on the compressive and shear response of the polymer, and so the discrepancy in the tensile predictions are acceptable. 


\section{Appendix E. Validating the indentation simulations}

To validate the choice of indenter geometry and finite element mesh, we compare the stress distribution obtained using our FE model with the theoretical solution for a flatended cylinder with a sharp corner, indenting an elastic half space, obtained by Sneddon [33]. As presented in Fig. E.22, the Sneddon solution is given as $a s_{\max } / \lambda \delta$ where $s_{\max }$ is the maximum shear stress, $a$ is the indenter radius, $\delta$ is the depth below the level of the undisturbed boundary that the punch penetrates and $\lambda$ is the Lamé elastic constant of the deformed medium, $\lambda=\nu E /(1+\nu)(1-2 \nu)$ where $\nu$ is the Poisson's ratio and $E$ is the Young's modulus.

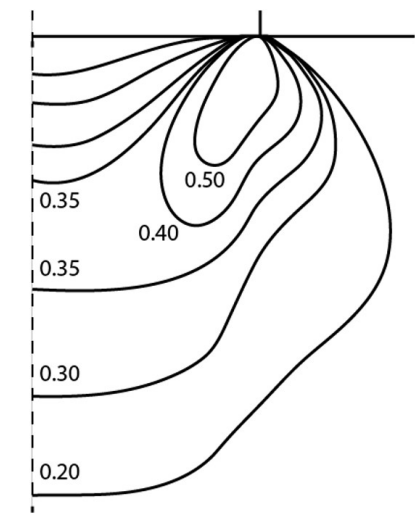

(a) Sneddon's solution [33]

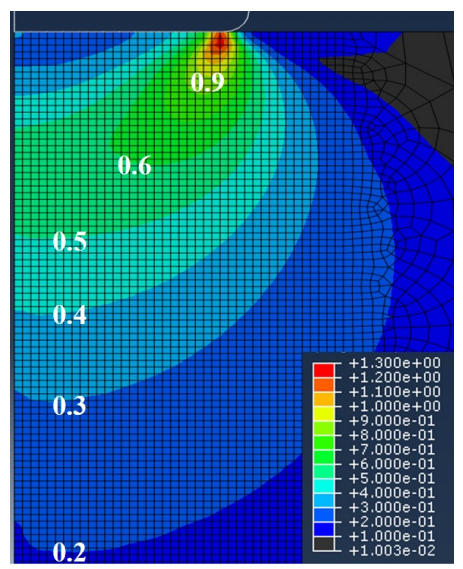

(b) FE indentation

Figure E.22: Sneddon's solution [33] for contours of normalised maximum shear stress in an elastic half space indented by a flat-ended cylinder with a sharp corner. Also presented are the contours of normalised maximum shear stress obtained in our axisymmetric FE simulation of the quasi-static indentation of a concrete block with a cylindrical, rigid indenter of corner radius of $1.5 \mathrm{~mm}$.

Using Abaqus/Explicit we model the indentation of an axisymmetric concrete block of radius $50 \mathrm{~mm}$ and height $100 \mathrm{~mm}$, indented to a depth, $\delta=0.05 \mathrm{~mm}$ at a speed, $0.1 \mathrm{~mm} \mathrm{~s}^{-1}$. The concrete model remains in its elastic regime under these conditions, and has a Young's Modulus, $E=28.3 \mathrm{GPa}$ and Poisson's ratio, $\nu=0.2$. The indenter is modelled as a rigid circular cylinder of radius $14.25 \mathrm{~mm}$, with a corner radius of $1.5 \mathrm{~mm}$, as described in Section 4.1. The contours of normalised maximum shear stress are plotted in Fig. E.22 and compared with Sneddon's solution. We observe that our FE model captures the distribution 
of stress in the substrate well, but noting that this comparison with theory is restricted to the elastic regime.

\section{Appendix F. Impact model: sensitivity to polymer modelling parameters}

Considering again the comparison between the FE model predictions and experimental measurements in Fig. 16, we now examine how the FE model (defined in Section 4) may be altered to improve agreement in the unloading phase of the impact.

First, we reconsider the elastomer/concrete interface condition. In Fig. F.23, we plot the FE prediction for the projectile velocity-time histories, assuming a frictionless contact condition between the elastomer and concrete. This model tends to provide a more accurate prediction for the projectile rebound velocities compared to when Coulomb friction (with a coefficient of friction $-\mu=0.8)$ is assumed at this interface. However, it is not clear from

the current experiments whether there is a sound physical basis for a reduction in interface friction during impact loading. 


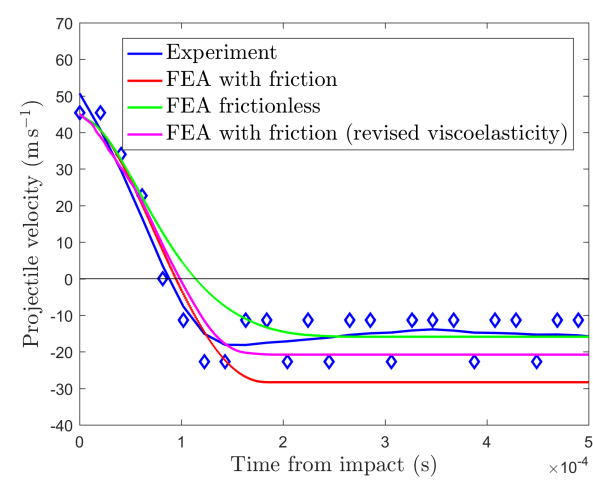

(a) $45 \mathrm{~m} \mathrm{~s}^{-1}$

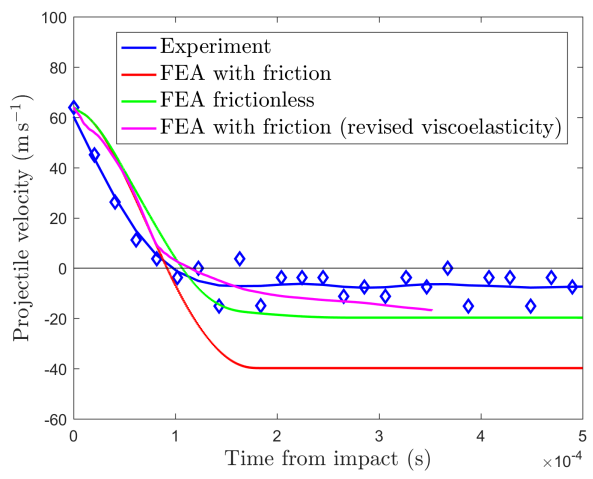

(b) $64 \mathrm{~m} \mathrm{~s}^{-1}$

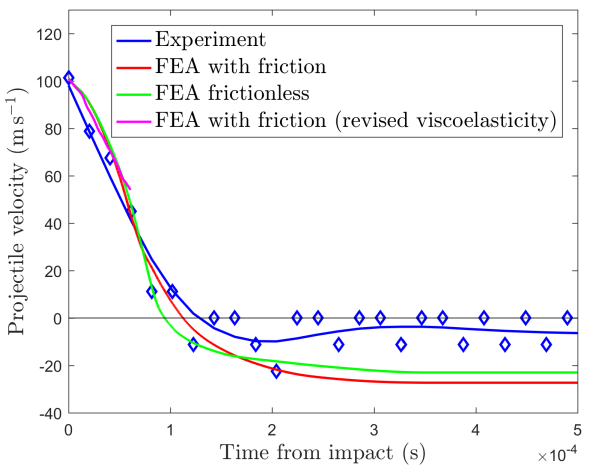

(c) $101 \mathrm{~m} \mathrm{~s}^{-1}$

Figure F.23: Projectile velocity-time history obtained from the impact experiments and the FE analysis for coated concrete specimens. The first FE model considers a friction coefficient, $\mu=0.8$ between the elastomer and concrete; the second considers frictionless contact at this interface and the third considers an alternative model to capture polymer hysteresis, as defined in the main text.

A further potential source of discrepancy is the Prony series representation of the viscoelastic behaviour, shown in Section 3.2 to underpredict the material hysteresis. Therefore, we attempt to develop an alternative means of representing the viscoelastic behaviour that does not rely on a Prony series. We use the built-in, 'Hysteresis' material model in Abaqus/Standard [21], developed to model the strain-rate-dependent, hysteretic behaviour of elastomers. The hyperelastic definition remains the same as that described in Section 3.2. The hysteresis parameters are as defined in the Abaqus User's Manual [21], with the following values used: stress scaling factor, $S=3.84$, positive exponent, $m=7.65$, exponent, $C=-0.467$ and constant, $A=8.15 E-54$. These parameters are derived using the commercially available 'MCalibration' software [35] based on a fit to uniaxial tension data measured 
at nominal strain rates between, $\dot{\epsilon}=10^{-2}-10^{2} \mathrm{~s}^{-1}$ and a compression load-unload test (described in 3.2) at a nominal strain rate $\dot{\epsilon}=10^{-3} \mathrm{~s}^{-1}$.

The use of this material model in Abaqus requires the implicit time integration version of the code. Compared to the calculations with explicit time integration, this is not able to solve the later phases of the projectile penetration for higher impact velocities (where there is a combination of large deformations and complex contact conditions). However, for load cases where a solution is obtained (impact speeds of $45 \mathrm{~m} \mathrm{~s}^{-1}$, with a partial solution at $64 \mathrm{~ms}^{-1}$ and $101 \mathrm{~ms}^{-1}$ ), there is an improved match with experimental measurements (Fig. F.23). 
[1] Davidson, J. S., Porter, J. R., Dinan, R. J., Hammons, M. I., Connell, J. D. (2004). Explosive testing of polymer retrofit masonry walls. Journal of Performance of Constructed Facilities, 18(2), 100106. http://doi.org/10.1061/(ASCE)0887-3828(2004)18:2(100)

[2] Davidson, J. S., Fisher, J. W., Hammons, M. I., Porter, J. R., Dinan, R. J. (2005). Failure Mechanisms of Polymer-Reinforced Concrete Masonry Walls Subjected to Blast. Journal of Structural Engineering, 131(8), 11941205. http://doi.org/10.1061/(ASCE)07339445(2005)131:8(1194)

[3] Amini, M. R., Isaacs, J., Nemat-Nasser, S. (2010). Investigation of effect of polyurea on response of steel plates to impulsive loads in direct pressure-pulse experiments. Mechanics of Materials, 42(6), 628639. http://doi.org/10.1016/j.mechmat.2009.09.008

[4] Amini, M. R., Simon, J., Nemat-Nasser, S. (2010). Numerical modeling of effect of polyurea on response of steel plates to impulsive loads in direct pressure-pulse experiments. Mechanics of Materials, 42(6), 615627. http://doi.org/10.1016/j.mechmat.2009.09.009

[5] Raman, S. N., Ngo, T., Mendis, P., Pham, T. (2012). Elastomeric Polymers for Retrofitting of Reinforced Concrete Structures against the Explosive Effects of Blast. Advances in Materials Science and Engineering, 2012, 18.

[6] Fallon, C.; McShane, G. J., Fluid-structure interactions for the air blast loading of elastomer-coated concrete, submitted for publication 2018

[7] Fallon, C.; McShane, G. J. Regime mapping the blast response of elastomer-coated concrete, in preparation 2018

[8] Xue, L., Mock, W., Belytschko, T. (2010). Penetration of DH-36 steel plates with and without polyurea coating. Mechanics of Materials. https://doi.org/10.1016/j.mechmat.2010.08.004

[9] Amini, M. R., Isaacs, J. B., Nemat-Nasser, S. (2010). Experimental investigation of response of monolithic and bilayer plates to impulsive loads. International Journal of Impact Engineering, 37(1), 8289. https://doi.org/10.1016/j.ijimpeng.2009.04.002 
[10] Amini, M. R., Amirkhizi, A. V., Nemat-Nasser, S. (2010). Numerical modeling of response of monolithic and bilayer plates to impulsive loads. International Journal of Impact Engineering, 37(1), 90102. https://doi.org/10.1016/j.ijimpeng.2009.04.005

[11] Roland, C. M., Fragiadakis, D., Gamache, R. M., Casalini, R. (2013). Factors influencing the ballistic impact resistance of elastomer-coated metal substrates. Philosophical Magazine, 93(5), 468477. https://doi.org/10.1080/14786435.2012.722235

[12] Roland, C. M., Fragiadakis, D., Gamache, R. M. (2010). Elastomer-steel laminate armor. Composite Structures, 92(5), 10591064. https://doi.org/10.1016/j.compstruct.2009.09.057

[13] Mohotti, D., Ngo, T., Mendis, P., Raman, S. N. (2013). Polyurea coated composite aluminium plates subjected to high velocity projectile impact. Materials and Design. https://doi.org/10.1016/j.matdes.2013.05.060

[14] Mohotti, D., Ngo, T., Raman, S. N., Ali, M., Mendis, P. (2014). Plastic deformation of polyurea coated composite aluminium plates subjected to low velocity impact. Materials and Design, 56, 696713. https://doi.org/10.1016/j.matdes.2013.11.063

[15] Mohotti, D., Ngo, T., Raman, S. N., Mendis, P. (2015). Analytical and numerical investigation of polyurea layered aluminium plates subjected to high velocity projectile impact. Materials and Design, 82, 117. https://doi.org/10.1016/j.matdes.2015.05.036

[16] Xue, Z., Hutchinson, J. W. (2007). Neck retardation and enhanced energy absorption in metal-elastomer bilayers. Mechanics of Materials, 39(5), 473487. https://doi.org/10.1016/j.mechmat.2006.08.002

[17] Xue, Z., Hutchinson, J. W. (2008). Neck development in metal/elastomer bilayers under dynamic stretchings. International Journal of Solids and Structures, 45(13), 37693778. https://doi.org/10.1016/j.ijsolstr.2007.10.006

[18] Mohagheghian, I., McShane, G. J., Stronge, W. J. (2016). Impact perforation of polymer-metal laminates: Projectile nose shape sensitivity. International Journal of Solids and Structures. https://doi.org/10.1016/j.ijsolstr.2016.01.010 
[19] Mohagheghian, I., McShane, G. J., Stronge, W. J. (2017). Quasi-static and impact perforation of polymer-metal bi-layer plates by a blunt indenter. Thin-Walled Structures. https://doi.org/10.1016/j.tws.2017.03.036

[20] Pham, T. M., Hao, H. (2016). Review of Concrete Structures Strengthened with FRP Against Impact Loading. Structures, 7, 5970. https://doi.org/10.1016/j.istruc.2016.05.003

[21] ABAQUS 2011, ABAQUS 6.11 Analysis User's Manual, Dassault Systemes, Providence, RI, USA

[22] Mohagheghian I., Impact response of polymers and polymer nanocomposites, $\mathrm{PhD}$ thesis, University of Cambridge, 2013

[23] Teychenne, D.C., Franklin, R.E., Erntroy, H.C., Design of normal concrete mixes, Department of the Environment, Building Research Establishment, Transport and Road Research Laboratory, 1975

[24] Simo J.C. and Ju J.W., Strain- and stress-based continuum damage models I. Formulation, International Journal of Solids and Structures, 1987, 23(7), 821-840

[25] Simo J.C. and Ju J.W., Strain- and stress-based continuum damage models II. Computational aspects, International Journal of Solids and Structures, 1987, 23(7), 841-869

[26] Mazars J. and Pijaudier-Cabot G., Continuum damage theory-Application to concrete, ASCE Journal of Engineering Mechanics, 1989, 115(2), 345-365

[27] Gatuingt F. and Pijaudier-Cabot G., Coupled damage and plasticity modelling in transient dynamic analysis of concrete, International Journal of Numerical and Analytical Methods in Geomechanics, 2002, 26, 124

[28] Kratzig W.B., and Polling R., An elasto-plastic damage model for reinforced concrete with minimum number of material parameters, Computers and structures, 2004, 82(15-16), $1201-1215$

[29] CEBFIP, CEB-FIP model code 1990: design code, 1993, Thomas Telford 
[30] Hordijk D. A., Local approach to fatigue of concrete, PhD Thesis 1991, Delft University of Technology, Delft

[31] Birtel V. and Mark P., Parameterised finite element modelling of RC beam shear failure, ABAQUS User's Conference, 2006, Taiwan

[32] Mauchien T.K., A fracture mechanics approach to accelerated life testing for cathodic delamination at polymer/metal interfaces, Master of Science in Engineering thesis, University of Texas at Austin, May 2013

[33] Sneddon, I.N. Boussinesq problem for a flat-ended cylinder, Proceedings of the Cambridge Philosophical Society 42, 29, 1946

[34] Serway R.A., Jewett J.W., Physics for scientists and engineers, 6th Edition, ThomsonBrooks/Cole, Belmont, CA, 2004

[35] MCalibration, Version 4.6.0, Veryst Engineering, 2017

[36] Yi J., Boyce M.C., Lee, G.F., Balizer, E., Large deformation rate-dependent stress-strain behavior of polyurea and polyurethanes, Polymer, 47, 2006, 319-329 